\title{
Consumer Behavior with Social Media Introduction to the Study
}

\author{
Dr.Terdsak Rojsurakitti \\ Rattana Bundit University
}

\begin{abstract}
Normally, people are rely on trust and familiarity as the primary way to reduce social uncertainty. In term of e-commerce, nature of business is unfamiliar with customer and one-time purchase. It is not interaction process. Therefore, people sometimes are entrusted to them. Among Asian people, familiarity is the primary concern of our culture. People behavior is tending to believe in whatever their familiar person says. That why many direct approach to consumers. Online also can use this trust to do e-commerce since there are some room for merchants can do on some website. Hence, social media come to play as important role on connecting people together through online. We can give definition to social media as group of application that use among the specific categories by characteristics, collaborative projects, blogs, social networking site, content communicates, virtual game, etc. Finally, we come to analyze the factors why people in Thailand especially in Bangkok use purchase the products through social media and trigger how to use this one as good pieces of work for business.
\end{abstract}

Keywords: Social Media, People behavior, e-commerce, People behavior, online, website

\section{INTRODUCTION}

In recent years, customer behavior and attitude has tremendous change. Consumer behavior involves the psychological processes that consumers go through in recognizing needs, finding ways to solve these needs, making purchase decisions (e.g., whether or not to purchase a product and, if so, which brand and where), interpret information, make plans, and implement these plans (e.g., by engaging in comparison shopping or actually purchasing a product).

While social media is an instrument on communication, like a newspaper or a radio, so social media would be a social instrument of communication. In Web 2.0 terms, this would be a website that doesn't just give you information, but interacts with you while giving you that information. This interaction can be as simple as asking for your comments or letting you vote on an article, or it can be as complex as Flixster recommending movies to you based on the ratings of other people with similar interests. Think of regular media as a one-way street where you can read a newspaper or listen to a report on television, but you have very limited ability to give your thoughts on the matter. Social media, on the other hand, is a two-way street that gives you the ability to communicate too. (http://webtrends.about.com/od/web20/a/social-media.htm). We would like to know. What is the customer behavior and attitude toward social media. Follow the theories; what drive customer to purchase product on social media; how long they need to consider and what factor to consider to purchase from social media; What the awareness customer get when they get information of the brand from social media and what they react to that media. So it should be survey about consumer behavior and attitude toward social media. And how we manage social media to be beneficial to any brand. 


\section{PURPOSE OF THE STUDY}

In this study, based on book by Sasiwan Serirat, 1994. In order to analyze consumer behavior the market must study about the target market, who are they, what do they buy, when do they buy, where do they buy, how do they buy and who influences the purchasing decision.

Then, consumers have specific problems that requires specific solution, hence the existing situation must always be the framework within which the decision-making process is viewed.

\section{THEORETICAL FRAMEWORK}

The research model for this study is book of Vijay Mahajan, 2001 for consumer experience through digital environment. In this model, goal to be attained, knowledge and experience, emotional state combine to determine the consumer's mind-set when the session begins.

A second important postulate of this model is that the consumer mind-set influences various aspects of his or her navigation in the digital environment. It determines which Web sites are visited, how much time is spent on individual Web sites, how much information is accessed, and what is learned and remembered. The mind set and the resulting navigation also influences the evaluation of the overall online experience, as well as specific feature such as particular websites, image of a particular company, and brand image. In addition, different mind-sets differ in their ability to create flow in consumers. Consumers in experiential mindsets are likely to be more susceptible to experience flow during a Digital Environment session then those in goal-oriented mind-sets. Future search can examine the relationship between mind-sets and the experience of flow.

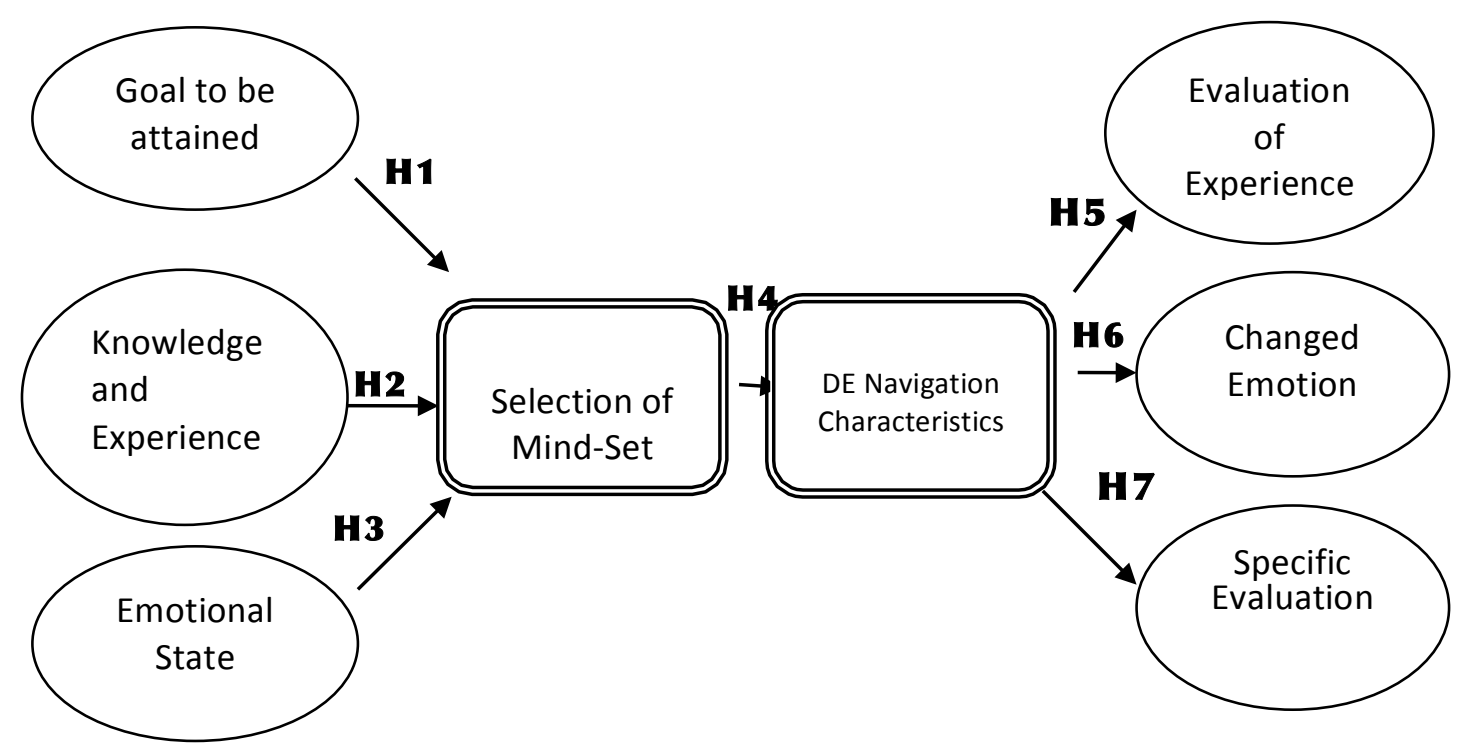




\section{Research Questions:}

1. Is there a relationship between goal to be attained and selection of mind-set?

2. Is there a relationship knowledge and experience and selection of mind set?

3. Is there a relationship between emotional state and selection of mind set?

4. Is there a relationship between selection of mind set and DE navigation characteristics?

5. Is there a relationship between DE navigation characteristics and evaluation of experience?

6. Is there a relationship between DE navigation characteristics and changed emotion?

7. Is there a relationship between DE navigation characteristics and specific evaluation?

\section{Hypotheses}

The research questions of this study give rise to the following Null Hypotheses (NH) and Research Hypotheses (RH):

NH1: The more unfavorable goal to be attained is, the lesser selection of mind set will be.

RH1: The more favorable goal to be attained is, the greater selection of mind-set will be.

NH2: The more unfavorable knowledge and experience is, the lesser selection of mind set will be.

RH2: The more favorable goal to be attained is, the greater selection of mind-set will be.

NH3: The more unfavorable emotional state is, the lesser selection of mind set will be.

RH3: The more favorable emotional state is, the greater selection of mind-set will be.

NH4: The more unfavorable selection of mind set is, the lesser DE navigation characteristic will be.

RH4: The more favorable selection of mind set is, the greater DE navigation characteristic will be.

NH5: The more unfavorable DE navigation characteristics is, the lesser evaluation of experience will be.

RH5: The more favorable DE navigation characteristics is, the greater evaluation of experience will be.

NH6: The more unfavorable DE navigation characteristics is, the lesser changed emotion will be.

RH6: The more favorable DE navigation characteristics is, the greater changed emotion will be.

NH7: The more unfavorable DE navigation characteristics is, the lesser specific evaluation will be.

RH7: The more favorable DE navigation characteristics is, the greater specific evaluation will be. 


\section{Literature Review}

The concept of Social Media is top of the agenda for many business executives today. Decision makers, as well as consultants, try to identify ways in which firms can make profitable use of applications such as Wikipedia, YouTube, Facebook, Second Life, and Twitter. Yet despite this interest, there seems to be very limited understanding of what the term "Social Media" exactly means; this article intends to provide some clarification. We begin by describing the concept of Social Media, and discuss how it differs from related concepts such as Web 2.0 and User Generated Content. Based on this definition, we then provide a classification of Social Media which groups applications currently subsumed under the generalized term into more specific categories by characteristic: collaborative projects, blogs, content communities, social networking sites, virtual game worlds, and virtual social worlds. Finally, we present 10 pieces of advice for companies which decide to utilize Social Media

Consumer behavior refers to the behavior that consumers display in searching for, purchasing, using evaluating, and disposing of products and services that they expect will satisfy their needs. The study of consumer behavior is the study of how individuals make decisions to spend their available resources (time, money, and effort) on consumption-related items. It includes the study of what they buy, why they buy it, when they buy it, where they buy it, how often they buy it, and how often they use it. (Leong G. Schiff man and Leslie Lazar Kanuk 1994)

The acts of individuals directly involved in obtaining and using economic goods and services, including the decision processes that proceed and determine these acts (J.F. Engel, 1987)

Therefore, marketer has come up with marketing mix. Marketing mix is a set of marketing tools that the firm uses to pursue its marketing objectives in the target market. Mc Cathy popularized a four-factor classification of these tools called the four Ps: Product, Price, Place (Distribution), and Promotion. (Kotler, 1997)

Every company has to decide how to divide the total marketing budget among the various tools in the marketing mix. Marketing mix is one of the key concepts in the modern marketing theory. (Kotler, 1997).

\section{Research Methodology Used}

Descriptive research will be used in this study where the raw data is transformed into the form that gives clear understanding and is easy to interpret data. It helps present data in a meaningful way (Sekaran, 1993). Descriptive research seeks to determine the answer to who, what, when, where and how questions (Zikmund, 2003). The research technique used in the study is survey instruments. Survey instrument is a research technique in which information is collected from a sample of people by using a questionnaire, a method of data collection based on communication with a representative sample of target population (Zikmund, 2003). The researcher used the sample survey by distributing the questionnaire to the respondents, in which they would indicate their opinion.

\section{Target Population-Samples}

Zikmund (2003) states, target population are the specific, complete group relevant to the research project. The target population in this study are all those who are familiar with social media.

\section{SURVEY INSTRUMENTS}

The questionnaire was designed to gather information on a theoretical model of mind-set formation and influence in digital environments (The MSFI model) The questionnaire 
consisted of 8 questions and can be divided into 2 sections.

The first section consisted of 8 questions designed to access drivers to social media. The first section attempts to find out the demographic characteristics of the respondents. Respondents rated all the statements given in the questionnaire on a five-point Likert scale, ranging from 'strongly disagree' to 'strongly agree'. The second section consisted 5 questions concerning gender, age, educational level, current position, and average income.

Before the actual survey administration, a pilot study was undertaken to ensure internal reliability of research items. The questionnaire was sent to 42 purchaser through online. Cronbach's coefficient alpha, SPSS 13.0 program, was used to assess the internal reliability of the research instruments. The pilot survey responses showed that the survey items had reliability scores above 0.7245 indicating an acceptable level of internal consistency (Nunnally, 1978). Additionally, for each of the construct's items, the corrected item-total correlation values exceeded 2.00. This means that the items for each of the construct are capable of independently measuring the construct. Table 1 shows the results of the analysis. Due to the satisfaction of the pilot results, all of the items were retained for the actual survey administration. The scale reliability value of the pretest is .7245 .

\section{SAMPLE SIZE}

For this research, the sample size is determined by estimating proportion and the procedure to use the sample proportion is to estimate the unknown population proportion. The researcher makes a judgment about confidence level and maximum allowance for random sampling error. Thus, the sample size for this research is calculated from the following formula (Zidmund, 2003)

$$
\underline{\mathrm{n}}=\mathrm{Z} 2 \mathrm{pq}
$$

E2

Where, $\mathrm{n}=$ number of items in sample

$\mathrm{Z} 2$ = square of the confidence level in standard error units

$\mathrm{P}=$ estimated proportion of success

$\mathrm{Q}=1-\mathrm{p}$, or estimated proportion of failures

$\mathrm{E} 2$ = square of the maximum allowance of error between the true proportion and the sample proportion. The allowable error is 0.05 or $5 \%$

The result of the calculation for the sample size is equal to 385 . However, for the data to be more reliable and accurate, 400 respondents were taken as the sample size.

\section{Respondents and Sampling Procedure}

In this research, the non-probability procedure will be used for selecting the respondents. In non-probability sampling the probability of any particular member of the population being selected is unknown (Zikmund, 2003)

For this research, the researcher collected the data from the population in Bangkok. The research will be scattered throughout the city of Bangkok.

The researcher collected the data by distributing the questionnaires via e-mail. The questionnaires were distributed using convenience sampling. Convenience sampling is the procedure used to obtain those units or people most conveniently available. 


\section{COLLECTION OF DATA}

The research used both primary and secondary data in the study. Primary data is the data collected and analyzed specifically for the research project at hand (Zikmund, 2003). The most common method of generating primary data is through a survey, in which information is gathered from a sample of people using a questionnaire. The questionnaire was translated to Thai for convenience and the researcher was assisted by Thai people. The questionnaire was distributed in by electronic mail to whom familiar with social media. There will be the question that the respondent used to purchase product through social media or not. If yes, we will let them be our respondents. The questions were explained in detail to the respondents. A total of 385 questionnaires were distributed.

Secondary sources are journals, internet, newspaper, magazine articles, textbook and previous studies. The purpose of going thoroughly with secondary material also was to find support and guidance for the research that has been undertaken.

\section{STATISTICAL TREATMENT OF DATA}

In this study, the confirmatory factor analysis (CFA) is utilized to test the model fit, validity, and reliability. CFA is performed to assess the factors and the loadings of variables. The Goodness-of-fit shows how well various indexes support the proposed model. The two subcategories of construct validity, convergent and discriminant validity; are carried out to verify that the multi-items' scales are applicable and provide accurate results. The reliability is tested via Cronbach's alpha coefficient ( ) and composite reliability. All computed values are compared with preceding researches to confirm the validity and reliability of the multi-items' scales and the good fit of the model.

To test the direct effects of the constructs, using LISREL 8.54 program, the maximum likelihood estimation (MLE) is used to perform the structural equation model (SEM). The study examined the effect of the predictors (attitude toward knowledge sharing, subjective norms, and organizational climate) and intention to share knowledge.

\section{Descriptive Statistics}

\section{RESULTS}

Initially, a total of 500 questionnaires were handed out. A total of 400 questionnaires were returned and used for the analysis, which indicated the response rate of $80.00 \mathrm{j} \%$. The samples consisted of 176 males and 224 females. Most of the participants were between the ages of 3140 and 23-30 years old with responses of 157 and 112 respectively. Additionally, most of them are university students, which accounted for 61.00\%. Majority of the respondents were university students with the sample size of 148 out of 400 . With regard to work household income, most of the respondents have about 10,000-19,999 baht. Table 1 shows descriptive characteristics of the respondents.

\section{Measurement Model}

In this study, there is only one first-order variables (Decision on purchasing products through social media). Decision on purchasing through social media is measured by eight indicators which include goal, knowledge and experience, emotional state, selection of mind-set, DE navigation, evaluation of experience, changed emotion, specific evaluation .As shown in Figure 3 , all eight indicators were sufficient and applicable in measuring the latent construct. In other words, decision on purchasing products through social media can be perceived, at least in the context of this study, by its indicators. 
To validate the measurement model, three types of validity were conducted: content validity, convergent validity, and discriminant validity. Content validity was established by ensuring consistency between the measurement items and the extant literature. This was done by experts' review and pilot-testing the instrument. The convergent validity was examined using composite reliability (CR) and average variance extracted (AVE) from the measures (Hair et al. as cited in Bock et al., 2005, p. 96). CR looks at the "measures of constructs that theoretically should be related to each other are, in fact, observed to be related to each other" (Trochim, 2006). As shown in Table 3, CR values is 0.89 , which were above the 0.70 threshold for field research (Hair et al. as cited in Lin, 2007, p. 129). For AVE, a score of 0.517 indicates acceptability (Hair et al. as cited in Lin, 2007, p. 129). Table 3 shows that AVE values is 0.517, which indicated that constructs was above the acceptability value. In addition, Table 3 exhibits loadings of the measures and squre multiple correlation. In general, the t-values are considered significant if they are greater than 2 or 2.576" (Hong et al., 2004, p. 107). As expected, all measures were significant on their path loadings at the level of 0.01. Moreover, as shown in Table 3, all indicators were then submitted to reliability analysis via Cronbach's alpha coefficient using SPSS 13.0 program. Cronbach's alpha measures how well a set of items (or variables) measures a single unidimensional latent construct. Theoretically, 0.70 is an acceptable level (Nunnally, 1978). Similar to CR, all constructs showed acceptable level of reliability.

The model-fit analysis was then performed to ensure the rectitude of the model. The model-fit was estimated using various indices provided by LISREL 8.54. The results are presented in Table 6. The overall chi-square statistic for the model was significant ( $\mathrm{X} 2=15.97, \mathrm{p}=0.00$ ). The ratio of the chi-square value relative to the degree of freedom $(X 2 / \mathrm{df}=15.97 / 11=1.45)$ was within the recommended value of 3 (Carmines \& Mclver as cited in Lin, 2007b, p. 127) which indicated a good model. GFI and AGFI were 0.99 and 0.97 , respectively. CFI, NFI, and NNFI, are three other indices of fit. Values normally range from 0 to 1 , with values greater than 0.9 representing reasonable model fit. This study observed values of $0.99,0.98$, and 0.98 for CFI, NFI, and NNFI respectively, all indicating good model fit. Finally, RMSEA illustrates the discrepancy between the proposed model and the population covariance matrix. The value was 0.034, which was within the recommended cut-off value of 0.08 for good fit (Byrne as cited in Lin, 2007b, p. 128).

\section{STRUCTURAL MODEL}

The casual structure of the hypothesized research model was tested using the structural equation model. Model testing was based on estimating the over-all fit indices of the structural model, as listed in Table 6. The ratio of X2 to degrees-of-freedom was 1.51 for the structural model, again within the recommended level of 3. Comparison of other fit indices with their corresponding recommended values provided evidence of a good model fit (GFI $=0.93$, AGFI = $0.92, \mathrm{CFI}=0.93, \mathrm{NFI}=0.94, \mathrm{NNFI}=0.94$, and RMSEA $=0.041$ ). In sum, all the model-fit indices exceeded their respective common acceptance levels, suggesting that the model fitted well with the data and thus an examination of path coefficients can be commenced.

\section{HYPOTHESES TESTING}

The structural equation model was performed to examine the hypothesized relationships among the constructs in the model. The results are discussed in the following sequence: Social Media constructs (Hypotheses 1,2,3,4,5,6,7 and 8. Properties of the casual paths, including path coefficients and t-values for each equation in the hypothesized model are presented in Figure 4. 


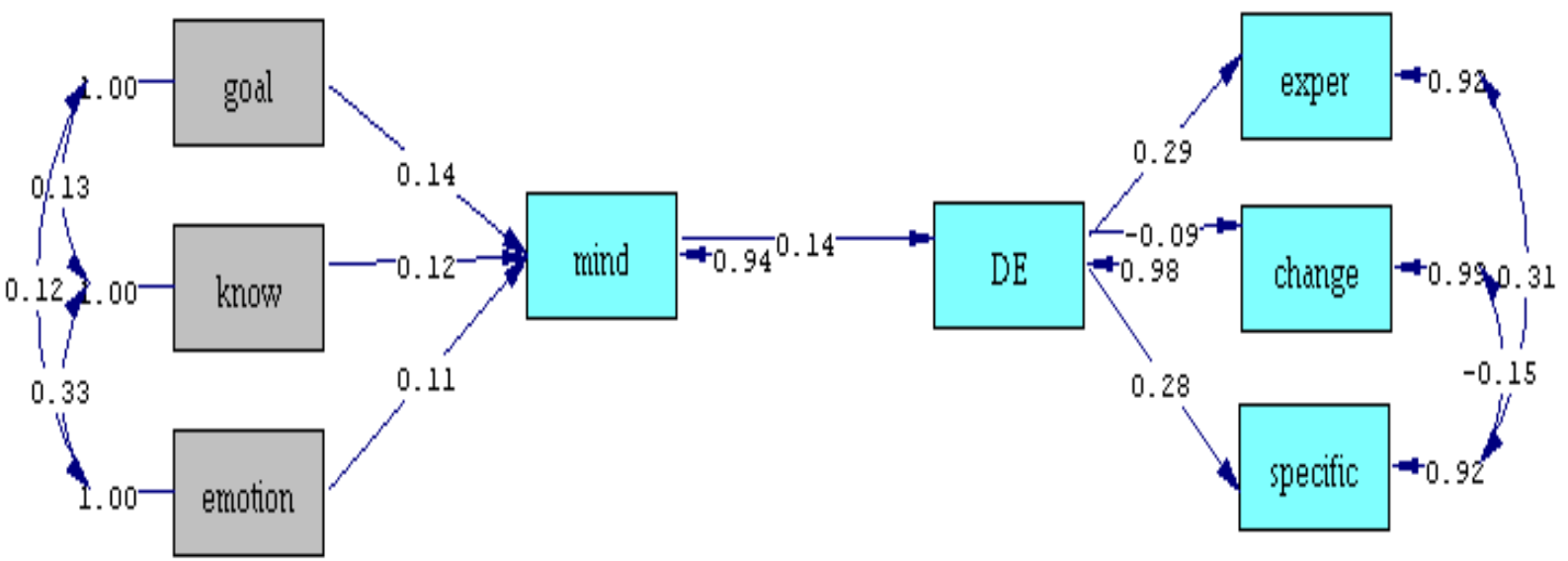

Figure 12 Results of Structural Model. (Utpal, 1973).

As shown in Table 6, the analytical results supported the hypotheses. H1 predicts a positive relationship between goal to be attained and selection of mind-set. The analytical results supported H2. H2, and H3, with a significant path coefficient of $0.04,0.12,0.11$ ( $<<0.001)$. It displayed significant relationships in hypothesized direction. These finding indicated that, goad to be attained, knowledge and experience and emotional state influence selection of mind-set

H4 displayed significant relationships in the hypothesized direction with path coefficients of 0.14 ( $\mathrm{p}<0.001)$. These findings indicated that, at least in Selection of Mind-set influence DE navigation characterisics. Furthermore, H5, H5, H7 (path coefficient equals to 0.29, 0.09 and $0.28(\mathrm{p}<0.05)$.

Finally, with regard to direct effect, the findings also showed diverse results. As posited, Tvalue of -1.84 ( $\mathrm{T}>1.96$ ), DE nativigation characteristics is not significant related to changed emotion. It means that DE navitgation characteristic is higher value, emotional changed will not changed.

\section{MANAGERIAL IMPLICATIONS}

Based on the findings, several recommendations are proposed to those leading social media initiatives or otherwise wanting to encourage purchase through online. First, selection of mind-set are to be encouraged. As the results indicated, Thai people need emotional bundle into their criteria of choice to achieve what they looking for (Goal to be attained) and emotional of their mind (emotional state). Thai business organizations may enhance their content and motivate promotion in to their content. Additionally, Thai business organization should used their knowledge and experience on line behavior to match their propose products into customer knowledge and experience by setting their target market. Then, they should prepare their content following to their customer knowledge and experience.

Second, Decision makers, as well as consultants, try to identify ways in which firms can make profitable use of applications such as Wikipedia, YouTube, Facebook, Second Life, and Twitter. Thai business organization should match their content with digital environmental navigation characteristics such as what kind of media should they match they content to facebook, twitter, hi5 on how many percent to each social media as percentage of their target will be.

Third, In additionally, postulate of the MSFI model is that the consumer mind-set influences various aspects of his or her navigation in the digital environment. It determines which Web sites are visited, how much time is spent on individual Web sites, how much information is 
accessed, and what is learned and remembered. Those are the effect to evaluation of experience and specific evaluation. This is why we should navigate our digital environmental to be well-prepare for Thai consumers to visit and feel good about our website or any social media related to products that we would like to sell.

Finally, In this study, based on book by Sasiwan Serirat, 1994. In order to analyze consumer behavior the market must study about the target market, who are they, what do they buy, when do they buy, where do they buy, how do they buy and who influences the purchasing decision. Therefore, we should target our market. Then, we should analyze who are they, what do they want, when will they buy and where and how will do they purchase to determine content to match with selection of mind-set and define digital environment characteristics in order to let them select the specific choice of their evaluation to our products.

\section{LIMITATION AND FUTURE RESEARCH}

The findings from this study must be interpreted in light of the study's limitations. First, the study took into consideration only a first order variable on theoretical model of mind-set formation and influence in digital environments (The MSFI model) (Utpal, 1973). Thus, factors were disregarded and no loop from evaluation of experience, changed emotion and specific evaluation to selection of mind-set. For this reason, it would be constructive to test other factors to determine their influence on digital navigation environment or selection of mind-set. Second, this study focused on the online purchase in Bangkok only thus the results cannot be interpreted as necessarily applicable to other provinces and countries. Therefore, to generalize the findings, it would be exceedingly useful to conduct similar research on other provinces and/or countries for comparative purposes. Third, the data collected are cross-sectional and not longitudinal; hence the hypothesized causal relationships could only be inferred rather than proven. Fourth, given that the sample size used for this research is moderately small, a larger sample is needed for the hypotheses to be robustly tested. A larger sample increases generalizability of the findings. Lastly, since the study did not take into consideration demographic factors, it would be interesting to examine possible variation in knowledge sharing behaviors in relation to such factors, for example, age, position, and/or average income. This is because people with diverse backgrounds might respond differently even to similar environment. As Riege (2005, p. 23) has suggested, at individual level, factors such as differences in experience levels, age differences, gender differences, position-based status, or differences in education levels can affect consumer behaviors. Thus, it might be constructive to conduct a comparative study on other different in individual level consumer behaviors, for instance.

\section{Reference}

Churchill, G. A. and Surprenant, C. (1982) An investigation into the determinants of customer satisfaction, Journal of Marketing Research, 9 (November), pp 491-504

Engel, Blackwell, and Kollat (1978) Consumer Behavior Hinsdale, IL: Dryden Pr.

Engel, J.F., Blackwell, R.D. \& Miniard, P.W. (1987) Consumer Behaviour: 5th ed, The Dryden Press, USA.

Fishbein, M., \& Ajzen, I. (1975). Belief, Attitude, Intention, and Behavior: An Introduction to Theory and Research. Reading, MA: Addison-Wesley.

Granger E. Westberg (2004), Good Grief by Granger E. Westberg, Augsburg Fortress, Publishers

James F. Engel, David T. Kollat, Roger D. Blackwell (1973) Consumer Behavior: Holt,Rinehart and Winston of Canada

Kotler \& Armstrong (1999) Principles of Marketing Upper Saddle River, NJ:Prentice Hall International 
McNeal (1982) Consumer Behavior: An Integrative Approach Boston : Little, Brown

Olshavsky and Miller (1972) Consumer Expectations Product Performance and Percieved Product Quality: (Journal of marketing research), vol IX (Feb 1972), pp. 19-21.

Oliver, R.L. and Desarbo, W.S.(1988). Response Determinants in Satisfaction Judgement. Journal of Consumer Research, 14 (March), 495-507.

Philips Kotler (1997) Marketing management: Analysis, planning, implementation, and control, Prentice Hall (Upper Saddle River, NJ)

Schnaars (1991) Marketing Strategiy, A Customer-Driven Approach New York: The Free Pr.

Serirat (1994) Marketing Strategies and Marketing Management Bangkok : Pathana

Suksa Pr Schiffman \& Kanuk (1994) Consumer Behavior London : Prentice-Hall International

Wayne D. Hoyer, Deborah J. Maclnnis (1997), Consumer Behavior, Fifth Edition: South-Western, USA

(http://www.consumerpsychologist.com/intro_Consumer_Behavior.html)

(http://webtrends.about.com/od/web20/a/social-media.htm).

(http://www.sciencedirect.com/science/article/pii/S0007681309001232) 